\title{
Fertility in the Northwest Region of Namibia
}

\author{
RIIKKA RAITIS
}

\author{
Lecturer \\ Department of Sociology \\ University of Helsinki \\ Helsinki, Finland
}

\begin{abstract}
The aim of this paper is to examine fertility in the Northwest Region of Namibia and the effects the principal proximate determinants have on fertility. The main data sources are the 1991 Population and Housing Census and the Namibia Demographic and Health Survey (NDHS) 1992. Indirect methods are used to estimate fertility, the Crude Birth Rate (CBR) and mortality on the basis of the census data and direct methods to calculate fertility from retrospective birth histories of NDHS data.

The level of fertility is higher in the Northwest Region than in other regions of the country. The first principal proximate determinant, the marriage pattern, seems to sustain high fertility in the Northwest Region compared to the South and Central Regions, but not in respect to the Northeast Region. Postpartum insusceptibility is longer in the Northwest Region than in Namibia on average, but shorter than in the Northeast Region. The use of contraceptives is exceptionally low in the Northwest Region compared to the other regions. The ideal number of children is highest in the Northwest Region. The levels of infant and child mortality are relatively low in the Northwest Region and in Namibia on average.
\end{abstract}

Keywords: fertility, proximate determinants of fertility, family planning, Namibia

\section{Introduction}

The aim of this paper is to examine fertility in the Northwest Region of Namibia and the effects the principal proximate determinants have on fertility. Comparisons with the other regions of Namibia and some sub-Saharan African countries are also made.

The regional division used in this paper is based on the 27 old districts of Namibia. The census data have been published based on this division. The collection of the Namibia Demographic and Health Survey (NDHS) data is also based on the old districts of Namibia. In the NDHS and this paper, these districts are used to build four larger regional units, i.e. the Northwest, Northeast, Central and South Regions. For example, the Northwest Region consists of the districts of Oshakati and Ondangwa. The Northwest Region is the area this paper is focusing on; historically this area was known as Ovamboland. At the time of the census and the NDHS, the Walvis Bay area was not part of Namibia; so it is excluded from both data-sets. 
Compared to some neighboring countries, the level of fertility is about the same in Namibia as in Zimbabwe. It is higher than in the Republic of South Africa and Botswana and lower than in Angola and Zambia (Cleland 1994, 72; RoN 1993a, 20).

The high level of fertility in sub-Saharan Africa has been affected by the early and universal marriage pattern, the low proportion of women using contraceptives and prolonged breastfeeding. Breastfeeding, causing long postpartum amenorrhoea, together with postpartum abstinence have traditionally been the most important factors reducing fertility below its maximum biological level. The ideal number of children and infant and child mortality have been high (e.g. Cochrane and Farid 1989).

During the last decade, however, there has been evidence showing that this pattern is not as stable as it has been assumed to be. A change has occurred in the reproductive behavior of women in some African countries, e.g. in the Republic of South Africa, Zimbabwe, Botswana, Kenya and parts of Nigeria. Some estimates show that fertility might be declining also in Namibia. In contrast to Botswana, the Republic of South Africa and Zimbabwe, the two Northern neighbors of Namibia, i.e. Angola and Zambia, do not yet show evidence of a fertility decline. Zambia is, according to some estimates, one of the African countries where the fertility transition may occur next. The decline of fertility has been associated with the increase in the use of contraceptives. This change has been explained by the rise in the level of female education, increased economical stress on large families, decreased infant and child mortality and increased official support to family planning services (Caldwell et al. 1992; Cleland 1994).

Infant and child mortality rates are slightly higher in Namibia than in Zimbabwe and Botswana, but much lower than in Zambia. Life expectancy at birth is longer in Southern Africa than in other parts of the continent (Bucht 1994, 149; IRD 1990; RoN 1993a, 69).

The infant mortality rate is 57 per 1,000 live births (rates are for the period $0-4$ years preceding the NDHS 1992). The child mortality rate is 28 per 1,000 live births. Comparing to the periods 5-9 years and 10-14 years before the survey, both infant and child mortality have slightly declined (RoN 1993a, 68-69).

Child mortality is slightly lower in urban than in rural areas, but the infant mortality rate is almost the same. Differences related to educational level are also small. The only clear pattern is lower child mortality among women with a secondary or higher education compared with children of women with a lower educational level. Usually the educational level of the mother has a stronger declining effect on infant mortality in sub-Saharan Africa. Regional differences in infant and child mortality are more significant. Levels of infant and child mortality are highest in the Northeast Region. The infant mortality rate is about the same in the Northwest Region as in the combined South and Central Regions. The most common causes of child mortality are diarrhoea, measles and acute respiratory infections. Malaria is a serious health problem especially in northern Namibia and tuberculosis in the southern part of the country (IRD 1990; NISER and UNICEF 1991; RoN 1993a, 68-69).

According to indirect estimates of mortality based on census data, life expectancy at birth (two years before the 1991 census) was about 60 years in Namibia on average and 61 years in the Northwest Region.

The population growth rate is high in Namibia. The annual growth rate was $3 \%$ between the years 1981 and 1991 on average. The growth rate in the Northwest Region is about the same as the national average ( RoN 1992, 15).

According to the 1991 census, 1.4 million people live in Namibia. The population of the districts of Oshakati and Ondangwa are 384,815 and 233,302, respectively. Together these two districts form the Northwest Region, where $44 \%$ of the country's total population lives on $6 \%$ of its total area ( $R o N 1992,1993 b)$. 
The area of Namibia is very sparsely populated. The population density of the whole country is 1.7 persons per square kilometer. The population distribution is very uneven, however, due to the apartheid policy before independence and variations in natural conditions. In the Northwest Region population density is 12 persons per square kilometer. The proportion of urban population is $32 \%$ in Namibia and $7 \%$ in the Northwest Region (RoN 1992, 1993b).

The age structure of Namibia is young. According to the 1991 census, $42 \%$ of the population is $0-14$ years old. The dependency ratio (the ratio of population under 15 years of age or over 64 years of age per 100 of population aged 15-64 years) is 87 in Namibia. The proportion of young and elderly people is larger in the Northwest Region than in Namibia on average. The dependency ratio is 113 in the Northwest Region.

The sex ratio (number of men per 100 women) is 95 in Namibia. In urban areas, however, men form the majority. In the Northwest Region the difference between the number of women and men is larger than in the whole country on average. The sex ratio is 82 in the Northwest Region and women are the majority in both urban and rural areas.

Population pyramids clearly show the small proportion of people in working ages, especially that of males, in the Northwest Region (Figure 1). One important reason for this is labor migration to the other parts of the country.

F i g u r e 1. Population pyramids of Namibia and the Northwest Region.

Namibia

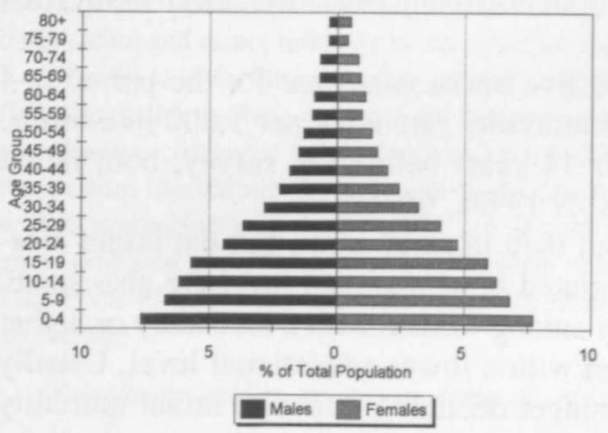

Northwest Region

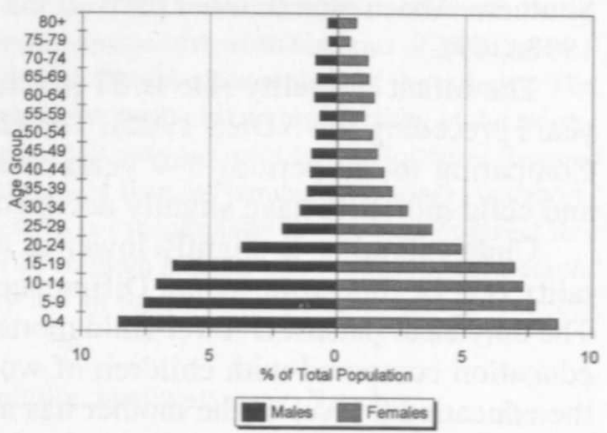

Data Source: RoN 1993c, Tables C01 and C01a.

About half of the population $(50.6 \%)$ in Namibia speaks Ovambo languages. The next largest language groups are Nama/Damara (12.5) \%, Kavango languages $(9.7 \%)$, Afrikaans $(9.5 \%)$ and Herero languages $(8 \%)$. The Northwest Region is very homogeneous in respect to languages: almost $99 \%$ of population speaks Ovambo languages.

\section{Data and methods}

This paper will mostly be based on the 1991 Population and Housing Census tables published in 1993 (RoN 1993b, 1993c, 1993d) and on the report and data of the Namibia Demographic and Health Survey (NDHS) 1992 (NDHS 1992; RoN 1993a). The census data are used for indirect estimates of fertility, the Crude Birth Rate (CBR) and mortality and for calculating general demographic indicators of population structure. 
The NDHS 1992 is a nationwide sample survey of 5,421 women aged 15-49 years. The aim of the survey was to provide information on fertility, family planning, child mortality and maternal and child health. The survey is part of the worldwide Demographic and Health Survey Program administered by Macro International Inc., Columbia, Maryland, USA and funded by the World Bank. The NDHS dataset used in some of the calculations in this paper has been obtained from Macro International Inc. Since Namibia achieved her independence in 1990, the 1991 census was the first national census of Namibia and the NDHS 1992 was the first national fertility survey (RoN 1993a).

Indirect fertility estimates from the census data have been done using the Brass method based on comparison of period fertility rates with reported average parities, i.e. the P/F ratio method (United Nations 1983). The idea of this method is to combine the age pattern of the period fertility rates with the level of fertility implied by the average parities of women younger than age 30 or 35 years. Observed age-specific fertility rates derived from data on births during the 12 months preceding the census are assumed to represent the true age pattern of fertility. These are adjusted to agree with the level of fertility indicated by average parities of women in younger age groups. The data on average parities are obtained from the census question about ever-born children.

Indirect mortality estimates from the census data have been made using Trussel's variant of the original Brass method of estimation of child mortality from information on children ever born and children surviving (United Nations 1983). The basic idea is that the proportion of children who have died of the children ever born to women in five-year age groups can be converted into estimates of probability of dying between birth and age $x$, i.e. $q(x)$.

The age pattern of fertility determines the children's length of exposure to the risk of dying in the different age groups of women. Therefore, an adjustment factor is used. This factor is the function of the average parity ratios indicating the age pattern of fertility and coefficients based on Coale-Demeny's Regional Model Life Tables (Coale and Demeny 1983). The Regional Model Life Tables are used in order to take into account the differences in the age pattern of mortality. In this study, the Model Life Tables West have been used. The probability of surviving $1(x)$, i.e. the complement of probability of dying between birth and age $\mathrm{x}$, can be converted into mortality levels in the Coale-Demeny Regional Model Life Tables. Trussel's variant also gives an estimate of the time period to which the probabilities refer.

Direct estimates of age-specific fertility rates are calculated from retrospective birth histories in the NDHS 1992. Births occurring to a specific aggregate of women are classified by terms of (1) period, i.e. completed years before the interview when the birth of a child occurred, (2) age, i.e. the completed years of mother at birth of the child and (3) cohort, i.e. women's age at the time of the interview (Verma 1980).

For a woman in cohort $\mathrm{c}$, the total exposure during the period $\mathrm{p}$ is divided into two parts: number of months spent in age a and the number of months spent in the previous age, depending on the month of her birthday and the month of the interview. Birth of a child to a woman in cohort $\mathrm{c}$ during the period $\mathrm{p}$ may occur at the woman's age a or at her previous age, depending upon the relationship between the month of the birth of the woman, the month of the interview and the month of the birth of her child. Births occurring at age a and previous age during a period $\mathrm{p}$ and length of exposure spent at age a and previous age during the period $\mathrm{p}$ are calculated for each individual woman in a cohort c. Data of individual women are aggregated in five year periods, five-year age groups of retrospective ages and five-year age groups for cohorts. ASFRs and TFR are calculated for the period 0-4 years before the survey. 
Fertility level

According to the NDHS 1992, the Total Fertility Rate (TFR) is 5.4 children per woman (for the period 0-3 years preceding the survey) (RoN 1993a). Indirect estimates of the census data result in a somewhat higher TFR, i.e. 5.9 (for the 12-month period preceding the census). Due to a smaller variety of background variables in the census both NDHS and census data are used in this article.

According to indirect fertility estimates based on census data, fertility is highest in the Northwest Region, where the TFR is 6.9. In the Northeast Region the TFR is almost as high, or 6.7. TFR is 5.5 and 4.2 in the Central and South Regions, respectively.

NDHS gives a lower TFR for every region: 6.7 in the Northwest Region, 6.0 in the Northeast Region, and 4.1 in the combined South and Central Regions (RoN 1993a).

The age pattern of fertility varies between the regions of Namibia (Figure 2). In the Northwest Region the peak level of fertility is in a relatively old age group, i.e. among the 30-34 year-old women. The fertility peak is wide: the fertility of age groups 25-29 and 35-39 is also high. In the Northeast Region the highest fertility levels are in younger age groups than in the Northwest Region. The fertility peak is composed of three age groups also in the Northeast Region, i.e. age groups 20-24, 25-29 and 30-34. In the Central and South Regions the fertility pattern is totally different from the pattern in the Northwest Region. Age-specific fertility rates are highest among women in age group 20-24 in the Central Region and those in age groups 20-24 and

F i g u re 2. Age-specific fertility rates by region.

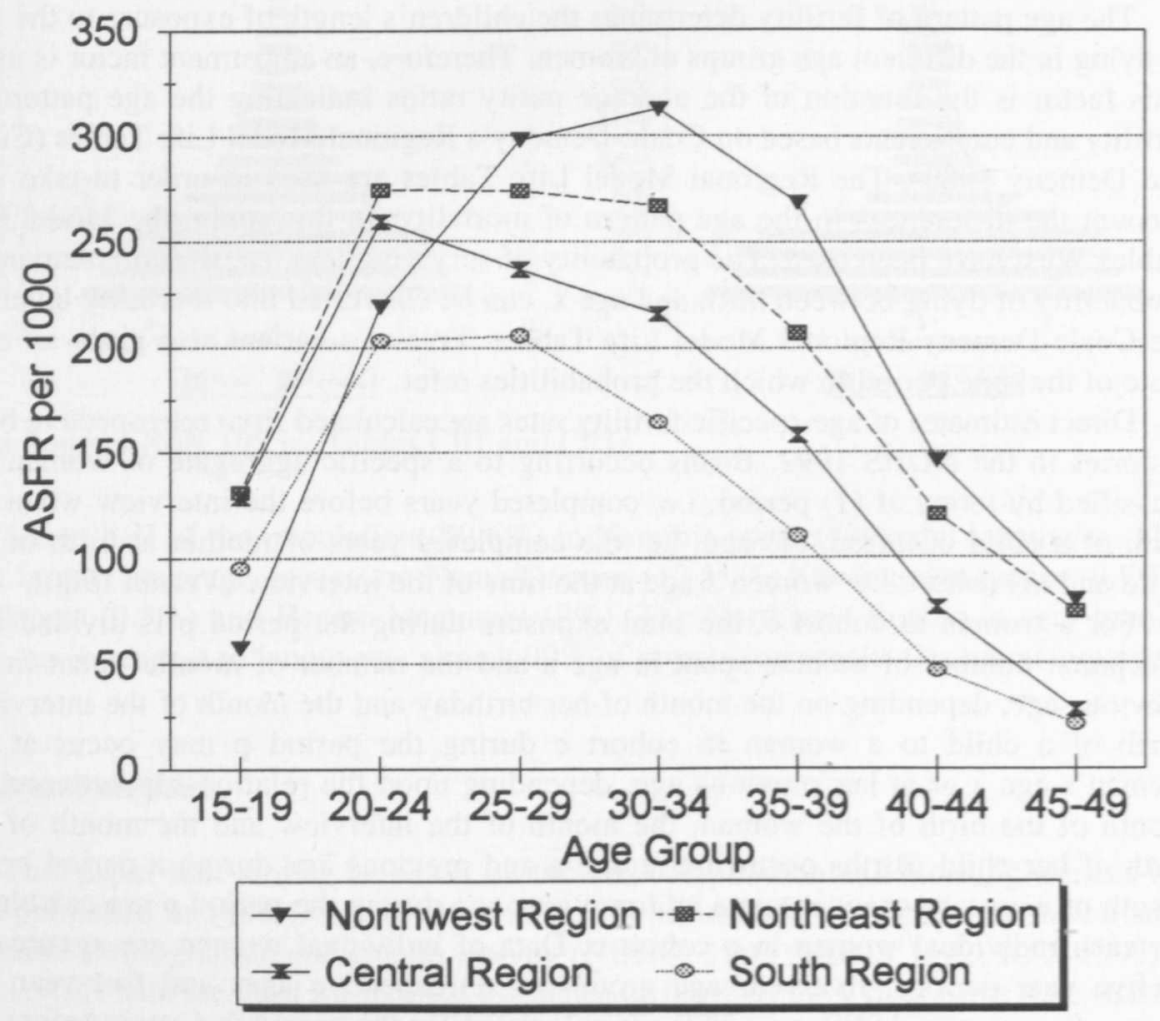

Data source: RoN 1993d, Tables F01 and F06. 
F i g u re 3. Total fertility rates by district.

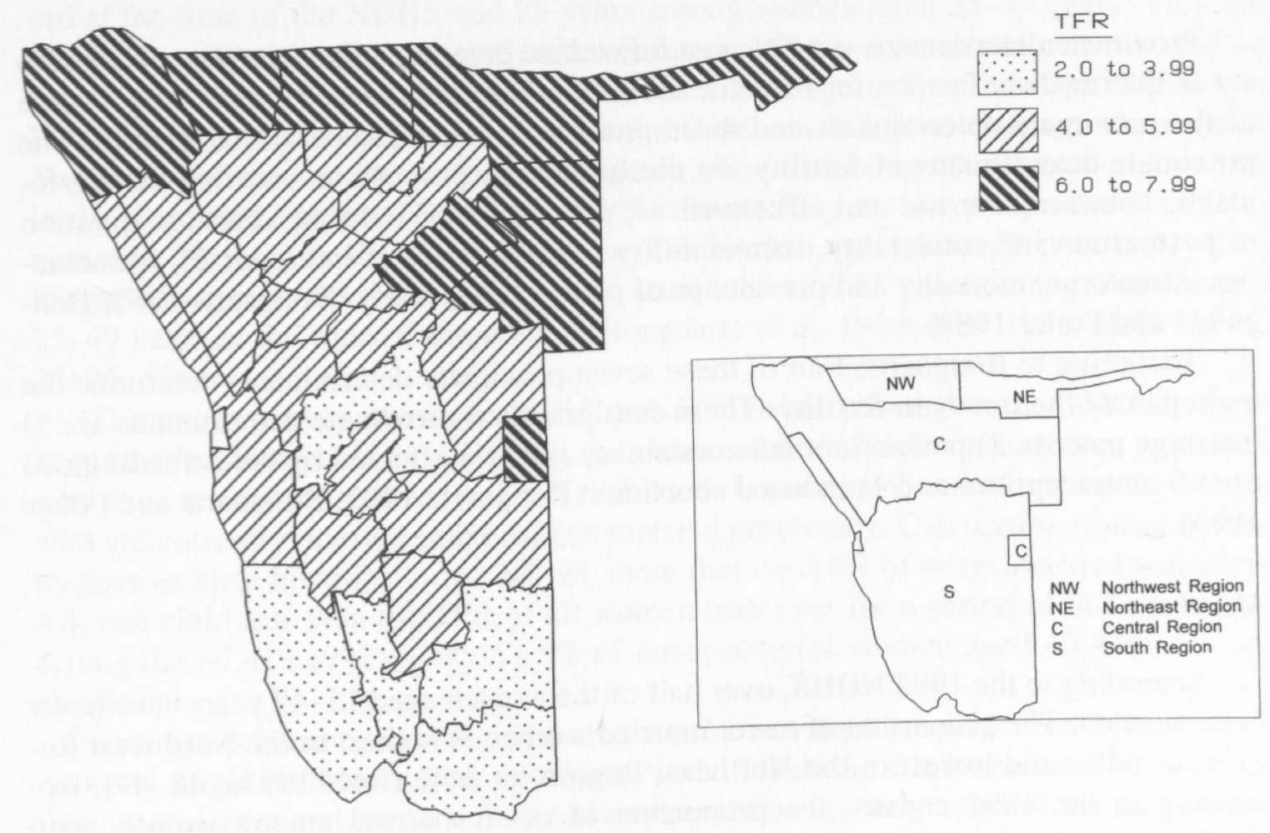

Data source: RoN 1993d, Tables F01 and F06.

25-29 in the South Region. Age-specific fertility rates are based on indirect census estimates.

The large regions mentioned above are not homogeneous in respect to fertility (Figure 3). Circumstances and populations vary in different parts of the country. For instance, the proportion of women over 15 years of age speaking »European» languages, i.e. Afrikaans, English, German and other European languages, is less than $2 \%$ in all of the districts where the TFR level is over 6 . The proportion of women speaking these languages varies from $36.3 \%$ to $66.6 \%$ in districts where the TFR is below 4 .

Fertility differs according to the urbanization of the place of residence and the socioeconomic status of women. According to the NDHS, fertility is higher in rural areas (TFR 6.3) than in urban (TFR 4.0) areas. Fertility decreases with an increase in the educational level. The TFR of women with no education is 6.6 , that of women who have completed primary school is 5.2 and the TFR of women with secondary or higher education is 4.1 ( $R o N$ 1993a, 20). According to the census, the proportion of women with no education in age group $25-34$ is lower $(14 \%)$ in the Northwest $\mathrm{Re}$ gion than in Namibia on average (18\%). Among women who have attended school, the proportion of women with only a primary education is larger and the proportion with a secondary or higher education is smaller in the Northwest Region than in Namibia on average. The proportion of literate females among rural females aged 10 years or more is higher $(75 \%)$ in the Northwest Region than in Namibia on average (68\%).

According to the NDHS, the Crude Birth Rate (CBR) is estimated to be 42 per 1,000 in Namibia ( $0-3$ years preceding the survey) (RoN 1993a). The adjusted CBR estimate for the 12 months preceding the 1991 census is somewhat higher, or 42.6 . The adjusted CBR is 48.4 in the Northeast Region, 43.8 in the Northwest Region, 39.8 in the Central Region and 36.2 in the South Region. 


\section{Proximate determinants of fertility}

Proximate determinants are the most immediate determinants of fertility. They also act as intermediate factors, for instance socioeconomic and cultural factors affect some of the proximate determinants and these proximate determinants affect fertility. The proximate determinants of fertility are the following: proportions married among females, contraceptive use and effectiveness, prevalence of induced abortion, duration of postpartum infecundability, fecundability (or frequency of intercourse), spontaneous intrauterine mortality and prevalence of permanent sterility (Bongaarts 1982; Bongaarts and Potter 1983).

According to Bongaarts, four of these seven proximate determinants determine the main part of the trends in fertility. These four principal proximate determinants are 1) marriage pattern, 2) postpartum infecundability (mainly affected by breastfeeding), 3) use of contraceptives and 4) induced abortions (Bongaarts 1982; Bongaarts and Potter 1983).

\section{Marriage}

According to the 1992 NDHS, over half of the women aged 15-49 years have never been married. The proportion of never married women is highest in the Northwest $\mathrm{Re}$ gion, or $64 \%$, and lowest in the Northeast Region, or 30\% (RoN 1993a, 48-49). According to the 1991 census, the proportion of never-married among women aged 15 years or more is $45 \%$ in Namibia on average and $51 \%$ in the Northwest Region. Among the 40-49-year-old women, the proportion of unmarried women is $15 \%$ in the Northwest Region and $17 \%$ in Namibia on average. In this age group, the proportion of legally married women is $50 \%$ in the Northwest Region and $52 \%$ in Namibia on average and the proportion of consensually married women is $19 \%$ in the Northwest Region and $17 \%$ in Namibia on average.

The proportion of unmarried women at the end of their reproductive period is high in Namibia compared to most sub-Saharan African countries. Usually the proportion of unmarried women in the age group 45-49 is 1-3\% in sub-Saharan Africa. The proportion of never-married women is high also in Botswana (Bongaarts, Frank and Lesthaeghe 1984; Cochrane and Samir 1989; IRD 1990).

Couples living together without getting legally married is a relatively common phenomenon in Namibia. According to the census, the proportion of those living in a consensual union is $13 \%$ among all women over 15 years old and 19\% among 30-39 year-old women. However, the proportion of women living in legal marriage is higher than the proportion of consensually married women in every age group. The proportion of legally married women is $30 \%$ among all women aged 15 years or more and over $45 \%$ among 30-39-year-old women.

Among women less than 30 years old, the proportion of unmarried women is larger in the districts of Oshakati and Ondangwa than in Namibia on average. The proportion of legally married or consensually married women is smaller among women less than 30 years old. Among women aged 30 years or more, the proportion of legally married women is only slightly smaller in Oshakati and Ondangwa than in Namibia on average. The proportion of consensually married women is about the same in the Oshakati District than in Namibia on average, but in the Ondangwa District their proportion is higher. The proportion of never-married women in the age group 45-49 is $11 \%$ in Namibia on average. There are wide regional differences in the proportion of unmarried women. It is the lowest in the Northeast Region, where in practice all women in this age group are married. The proportion of never-married women in the age group $45-49$ is $14 \%$ in the Northwest Region. 
The median age at first marriage is 23 years among women who were $45-49$ years old at the time of the NDHS and 25 years among women aged $25-49$ years. This age at first marriage is high compared to sub-Saharan African countries in general. Among the neighboring countries, Botswana also has a high age at first marriage, while it is lower in Angola and Zimbabwe. Regional differences in age at marriage are wide in Namibia. The median age at first marriage is 19 years among 45-49-year-old women in the Northeast Region, 23 years in the Northwest Region, 26 years in the South $\mathrm{Re}$ gion and 27 years in the Central Region. The median age at first birth is lower than the median age at first marriage: 21 years compared with 25 years among women aged 25-49 years at the time of the survey (Bongaarts et al. 1984; IRD 1990; RoN 1993a, $25-26,50)$.

The mean number of ever-born children is high also among women who have not been married. Compared by age group, the mean number of children ever born to women who have never been married is $1.5-0.6$ children lower than the number born to women who are currently married or have been married previously. Calculations based on retrospective birth histories in the NDHS show that the TFR of never married women is 4.4 , one child less than the TFR of all women (rates are for a period of 0-4 years preceding the NDHS 1992). Only $11.3 \%$ of never-married women aged $45-49$ years are childless.

Teenage pregnancy is a problem that results in a high proportion of school dropouts and single mothers among adolescent girls. The lack of information on reproductive health issues and inaccessibility of contraception are only some of the reasons behind this phenomenum. However, parents usually have negative attitudes towards sex education in schools. Teenage pregnancies and premarital sexual relationships are relatively common phenomena in many sub-Saharan African countries, despite traditional values against them (Bongaarts et al. 1984; Caldwell et al. 1992; Hailonga 1993; Hubbard and Tapscott 1992).

The proportion of currently married women living in polygynous unions is highest in the Northeast Region (25\%) and second highest in the Northwest Region (15\%) (RoN 1993a, 48-49).

\section{Postpartum infecundability and abstinence}

Postpartum amenorrhoea, i.e. the period when ovulation has not yet returned after birth, plays an important role in delaying new pregnancies and reducing fertility among populations where family planning is not practiced by use of contraceptives. Prolonged breastfeeding increases the length of postpartum amenorrhoea. In many traditional societies, postpartum abstinence is also practiced: after giving birth women are not supposed to have intercourse for some period of time. Together these two, postpartum amenorrhoea and abstinence, provide protection against pregnancies, i.e. a period of postpartum insusceptibility.

The median length of postpartum amenorrhoea is 8 months in Namibia and that of postpartum abstinence is 6 months. Women are protected against pregnancy, i.e. insusceptible, by either amenorrhoea or abstinence 13 months after they have given birth. Women younger than 30 years have a shorter period of postpartum amenorrhoea but a longer period of abstinence than older women. Among women living in urban areas both postpartum amenorrhoea and abstinence are shorter than among those living in rural areas. An increase in the level of education decreases postpartum amenorrhoea. The insusceptible period is 14 months long among women with no education and 10 months long among women with a secondary or higher education. The duration of postpartum abstinence and breastfeeding varies remarkably between the different areas of sub-Saharan Africa (Bongaarts et al. 1984; RoN 1993a, 54-55). 
Women in the Northeast Region have the longest period of postpartum amenorrhoea and women in the Northwest Region have the longest period of postpartum abstinence. In the South and Central Regions both amenorrhoea and abstinence are shorter than in the other two regions. The length of postpartum insusceptibility is the longest in the Northeast Region (17 months) and the shortest in the South Region ( 8 months). The length of the insusceptible period is 15 months in the Northwest Region. The length of breastfeeding has a similar pattern: it is longest in the Northeast Region and shortest in the South Region. The median duration of breastfeeding is 17.3 months in Namibia, but the median duration of full breastfeeding, i.e. breastfeeding without any other supplements than water, is only 1.7 months (RoN 1993a, 55, 119).

\section{Contraception and abortion}

Knowledge of contraceptive methods is relatively good in Namibia: $90.4 \%$ of currently married women and $88.5 \%$ of all women know some modern method. In the Northwest Region the percentage of currently married women knowing any modern method is 82 , the lowest of all regions. Knowledge of sources of family planning methods is $82 \%$ among currently married women in the whole country. Only $67 \%$ of currently married women in the Northwest Region know where to obtain contraceptives. Knowledge is better in urban than in rural areas and increases with an increase in educational level (RoN 1993a, 30-31).

The best known methods are injectives, which are familiar to $85 \%$ of currently married women in Namibia. The next best known methods are the pill (82\%), condoms $(71 \%)$ and female sterilization $(60 \%)$. Only $41 \%$ of currently married women knew any traditional method. The best known traditional methods are withdrawal $(32 \%)$ and periodic abstinence (30\%). Over $70 \%$ of currently married women knew where to obtain information or devices concerning injectives (76\%) or the pill (73\%). Surprisingly few, only $52 \%$ of currently married women, knew where to obtain condoms (RoN 1993a, 30).

The proportion of currently married women currently using any method of family planning is $29 \%$ in Namibia on average. The proportion of currently married women using modern methods is $26 \%$. Only $9 \%$ of currently married women are using any contraceptive method in the Northwest Region, and the proportion using modern methods is $7 \%$. This rate is much lower than in other regions: the proportion of currently married women using any method is $52 \%$ in the South Region, $32 \%$ in the Central Region and $22 \%$ in the Northeast Region. Use of contraceptives is more common in urban than in rural areas and increases with education (RoN 1993a, 35).

The most commonly used modern methods are the pill, injectives and female sterilization. Pills and injectives are, however, subject to high dropout rates in Namibia. Pills have the highest failure rate when measured in pregnancies. Rumors and side effects are important reasons why women stop using contraceptives, especially the injective contraceptive Depo-Provera has been accused of causing side effects. The pill and injectives are, in practice, the only alternatives offered to women in some places (Ahrenson-Pandikow 1992; RoN 1993a, 35).

The most popular traditional method is herbs, which are used by $1.8 \%$ of women. Herbs are the most commonly used method in the Northeast Region, where over $8 \%$ of women use them. In other regions their use is negligible. The second most popular traditional method is periodic abstinence, used by $0.7 \%$ of currently married women in Namibia (RoN 1993a, 35).

According to the NDHS, the most common reason for not using contraceptives is the desire to have more children. The second most common reason was a lack of knowl- 
edge (RoN 1993a, 42). The use of contraceptives is also diminished by the fear of side effects and restricted choices of contraceptive methods (Ahrenson-Pandikow 1992).

Half of the currently married women who knew at least one method reported that both she and her husband approve of family planning. Sixteen percent of women who approve of family planning said that their husband disapproved of it and $15 \%$ of the women said that both she and her husband disapprove of family planning. In the Northwest Region $30 \%$ of the women reported that both she and her husband disapprove of family planning, this proportion being much higher than among women living in other regions. The proportion of women reporting that both husband and wife approve of family planning is $33 \%$ in the Northwest Region. The percentage with the wife approving of family planning but the husband not approving is about the same in the Northwest Region as in Namibia on average. The proportion of women disapproving of family planning is $27 \%$ in Namibia on average and $42 \%$ in the Northwest Region (RoN 1993a, 45).

In Namibia the ideal number of children is five on average. Thus, it is almost as high as the TFR in Namibia. The ideal number of children declines when the level of education increases. The ideal number of children among women with no education is 6.6 and among women with a secondary or higher education it is 4.0 . The ideal number of children is higher in rural than in urban areas. There are also regional differences in the ideal number of children: it is highest in the Northwest Region (6.2) and second highest in the Northeast Region (5.8). The ideal number of children is 4.4 in the Central Region and 3.3 in the South Region. There are probably many cultural and economic reasons behind the large ideal number of children, such as women's socialization, which emphasizes their role as childbearers and mothers, and women's need for the assistance of children in food production (Hubbard and Tapscott 1992; NISER and UNICEF 1991; RoN 1993a, 63).

Abortion is illegal in Namibia except in a few extreme circumstances, but it is claimed that illegal abortions are common in Namibia. The discussion of the liberalization of the law on abortion has led to a heated debate and the foundation of two movements: Pro-Choice which campaigns for the liberalization of the abortion law and Pro-Life campaigns against the legalization of abortion (Hubbard and Tapscott 1992; Kavari 1994).

\section{Other proximate determinants}

Frequency of intercourse has impact on the probability of conceiving. Coital frequency is affected by e.g. spousal separation. Large scale male labor migration causes spousal separation in Namibia, but its impact is somewhat reduced by polygyny: many of the men have (unofficial) wives in both the area of the origin and the area of the destination of the migration (Bongaarts et al. 1984; NDT 1994).

Intrauterine mortality, i.e. spontaneous abortions and stillbirths, is generally quite similar among all human populations. Stillbirths may be more common in Africa than elsewhere, but the proportion they form of intrauterine mortality is so small that their impact on fertility differentials between the populations is negligible (Bongaarts and Potter 1983).

The level of primary infertility may be estimated on the basis of the proportion of married women who remain childless. According to the NDHS, $2.6 \%$ of ever married women and $3.4 \%$ of all women aged 45-49 years are childless (RoN 1993a, 22-23). The proportions of childless women are higher in the 1991 census than in the NDHS: the proportion of ever-married, childless women in the age group 45-49 is $3.5 \%$ and that of all women aged $45-49$ is $4.6 \%$. The proportion of childless women among all women aged $45-49$ is $3.7 \%$ in the Northwest Region. The standard level of childless- 
ness is about $3 \%$ in a number of populations. The highest levels of infertility are found in central Africa, where $20 \%$ of women between $45-49$ years of age may be childless (Bongaarts, Frank and Lesthaeghe 1984). In areas where infertility is common gonorrhea is prevalent. Besides primary infertility, there is also secondary infertility, i.e. infertility that starts after a woman already has one or more children.

\section{Conclusions}

Despite the relatively small area of the Northwest Region, $44 \%$ of the total Namibia population lives there. The population density is higher in the Northwest Region than in Namibia on average. The proportion of the female population is higher in the Northwest Region than in Namibia on average, and the dependency ratio is high because of a large proportion of both young and elderly population. This is a typical population structure in a population where large scale out-migration of people of working age occurs. The population is very homogeneous in respect to language: almost everyone speaks Ovambo languages.

Compared with other regions and the national average, the level of fertility is high in the Northwest Region. The first proximate determinant examined, the marriage pattern, seems to sustain fertility at a higher level in the Northwest region than in the Central and South Regions, because age at first marriage is higher in the Central and South Regions than in the Northwest Region. Women in the Northeast Region, however, marry younger than women in the Northwest Region.

In Namibia, however, the TFR of unmarried women is only one child lower than that of all women, and women often start childbearing before their first marriage. Besides the high fertility of unmarried women, there are some other interesting phenomena in the marriage pattern of Namibia. The proportion of consensually married women is relatively high in Namibia, and compared to many other sub-Saharan African countries (e.g. Cochrane and Farid 1989), a large proportion of women stay unmarried until the end of their reproductive period.

The period of postpartum insusceptibility is long in the Northwest Region compared to the Central and South Regions, but shorter than in the Northeast Region. This is a reflection of the period of breastfeeding being second longest in the Northwest Region compared with other regions. The period of postpartum abstinence being longest also increases the relatively long period of postpartum insusceptibility. The use of contraceptives is very low in the Northwest Region. In respect to this proximate determinant, the situation in the Northwest Region differs considerably from the situation in all other regions.

Another interesting issue is the low infant and child mortality in Namibia. They are low everywhere else but in the Northeast Region: in this respect the Northwest Region belongs to the same group as the South and Central Regions. Usually fertility and the ideal number of children decrease when infant and child mortality are low, as they have decreased in the South and Central Regions. In the Northwest Region, however, fertility is still high. Infant mortality also seems to be less sensitive to the educational level of the mother than in sub-Saharan Africa on average.

\section{References}

Ahrenson-Pandikow, Helena. 1992. Survey of Attitudes Towards the Use of Contraceptives in Namibia. Windhoek, Namibia: Namibian Institute for Social and Economic Research, University of Namibia (NISER). (Paper prepared for the UNFPA). 
Bongaarts, John. 1982. The fertility-inhibiting effects of the intermediate fertility variables. Studies in Family Planning 13(6/7): 179-89.

Bongaarts, John and Robert G. Potter. 1983. Fertility, Biology and Behavior. Studies in Population. London: Academic Press Ltd.

Bongaarts, John, Odile Frank and Ron Lesthaeghe. 1984. The proximate determinants in sub-Saharan Africa. Population and Development Review 10(3): 511-37.

Bucht, Birgitta. 1994. Mortality trends in developing countries: a survey. In: The Future of World Population: What Can We Assume Today?, edited by Wolfgand Lutz, pp. 147-64. London: Earthscan Publications Ltd and Laxenburg, Austria: International Institute for Applied Systems Analysis.

Caldwell, John C., I.O. Orubulove and Pat Caldwell. 1992. A new type of fertility transition in Africa. Population and Development Review 18(2):212-42.

Cleland, John. 1994. A regional review of fertility trends in developing countries: 1960 to 1990. In: The Future of World Population: What Can We Assume Today?, edited by Wolfgand Lutz, pp. 55-82. London: Earthscan Publications Ltd and Laxenburg, Austria: International Institute for Applied Systems Analysis.

Coale, Ansley J. and Paul Demeny. 1983. Regional Model Life Tables and Stable Populations. Second Edition. Studies in Population. New York: Academic Press Ltd.

Cochrane, Susan and Samir F. Farid. 1989. Fertility in Sub-Saharan Africa: Analysis and Explanation. World Bank Discussion Papers 43. Washington: The World Bank.

Hailonga, Panduleni. 1993. A Study to Identify Adolescents' Knowledge, Attitudes and Beliefs Towards Teenage Pregnancy. Windhoek, Namibia: Ministry of Health and Social Services.

Hubbard, Dianne and Chris Tapscott. 1992. Country Gender Analysis Namibia. Windhoek, Namibia: Swedish International Development Authority (SIDA).

IRD (Institute for Resource Development). 1990. An Assessment of DHS-I Data Quality. DHS Methodological Reports 1. Columbia, Maryland: Institute for Resource Development/Macro Systems, Inc.

Kavari, Franna. The great abortion controversy. The Namibian, March 11, 1994: 7.

NISER (Namibian Institute for Social and Economic Research, University of Namibia) and UNICEF. 1991. A Situation Analysis of Children and Women in Namibia. Windhoek, Namibia.

NDHS 1992. Namibia Demographic and Health Survey 1992 dataset.

NDT (Namibia Development Trust). 1994. Improving the Legal and Socio-Economic Situation of Women in Namibia: Uukwambi, Ombalantu and Uukwanyama Integrated Report. Volume 1. Windhoek, Namibia.

RoN (Republic of Namibia). 1992. 1991 Population and Housing Census. Preliminary Report. Windhoek, Namibia: National Planning Commission, Central Statistics Office.

-. 1993a. Namibia Demographic and Health Survey 1992. Ministry of Health and Social Services, Namibia and Demographic and Health Surveys Macro International, Inc. Columbia, Maryland and Windhoek, Namibia.

-. 1993b. 1991 Population and Housing Census. Report A: Statistical Tables. Volume I: Geographical, Migration and Household Characteristics. Windhoek, Namibia: National Planning Commission, Central Statistics Office.

-. 1993c. 1991 Population and Housing Census. Report A: Statistical Tables. Volume II: Demographic, Social, Literacy and Educational Characteristics. Windhoek, Namibia: National Planning Commission, Central Statistics Office.

-. 1993d. 1991 Population and Housing Census. Report A: Statistical Tables. Volume IV: Fertility and Disability. Windhoek, Namibia: National Planning Commission, Central Statistics Office.

United Nations. 1983. Manual X: Indirect Techniques for Demographic Estimation. Department of International Economic and Social Affairs. Population Studies 81, ST/ESA/SER.A/81. New York.

Verma, Vijay. 1980. Basic Fertility Measures from Retrospective Birth Histories. World Fertility Survey Technical Bulletins 4. International Statistical Institute. 